\title{
Un Caso de Embarazo Extrauterino Avanzado
}

\author{
Dr. Fernando Sánchez T.
}

HISTORIA CLINICA

Historia $N^{0} 56951$ del Instituto Materno Infantil de Bogotá. Corresponde a una paciente de 22 años que ingresa el 27 de Enero de 1960 por haber sentido una hora antes dolor abdominal de aparición súbita, intenso, con duración aproximada de diez minutos, localizado en la región hipogástrica y seguido de lipotimia. Posteriormente su intensidad disminuyó, generalizándose a todo el abdomen y exacerbándose con los cambios de posición.

Antecedentes generales sin importancia. Menarquia a los 14 años, ciclos $30 \times 4$.

Antecedentes obstétricos: Un embarazo a término con parto espontáneo, tres años antes. Amenorrea desde el 24 de Mayo de 1959, sin referir dolor ni metrorragia en los seis meses siguientes. En los dos últimos meses sintió dolores pélvicos intermitentes, de escasa intensidad. Dos días antes de su ingreso hubo discreta hemorragia genital. Los movimientos fetales fueron percibidos momentos antes del accidente actual. No asistió a consulta prenatal porque "no lo considieró necesario".

Se observa una paciente quejumbrosa, que tiende a permanecer en decúbito lateral, polipnéica, con facies angustiosa. Palidez marcada de piel y mucosas. Tensión arterial 60/40; pulso débil con frecuencia de 120 al minuto; temperatura axilar $36.5^{\circ}$. Abdomen globuloso, distendido y uniformemente doloroso. La macicéz hepática está presente. Por percusión se reconoce una tumefacción mediana. que por su tamaño correspondería a un útero grávido de $61 / 2$ meses y de consistencia renitente a la palpación. El dolor y la distensión impiden precisar su contenido. No se auscultan ruidos fetales. Al tacto vaginal el cuello es central, largo. blando, cerrado; fondos de saco libres y muy dolorosos. No hay metrorragia.

Cuadro hemático: Glóbujns rojos 2'050.000, hemoglobina 7.5 gr., valor globular $21 \%$, leucocitos 16.000 , neutrófilos $75 \%$, linfocitos $22 \%$, monocitos $3 \%$.

Se aplican plasma y sangre total. 
Con diagnóstico de presunción de embarazo extrauterino complicado, o de embarazo tópico y quiste torcido del ovario o de torsión del útero grávido, se somete la enferma a una laparotomía de precisión, hora y media después de su ingreso.

Al abrir la pared abdominal se halla la cavidad peritoneal inundada de sangre. Se perfora un saco membranoso y aflora un feto muerto, masculino, de 2.360 grs., bien conformado y sin signo alguno de maceración. Se liga y se secciona el cordón umbilical. El útero se encuentra aumentado unas cuatro veces su tamaño normal y no se advierte en su superficie solución alguna de continuidad. La placenta se halla insertada en la cara peritoneal del fondo uterino invadiendo el cuerno izquierdo, el cual se aprecia muy alargado. El ovario correspondiente está fuertemente adherido a las membranas ovulares. El anexo derecho es aparentemente normal. La hemorragia que se origina en el sitio de inserción de la placenta es tan intensa que obliga a practicar histerectomía, contrariando el deseo de dejar aquella en su sitio. Al terminar la intervención se habían transfundido 2.000 c.c. de sangre.

Ocho días después Ia paciente es dada de alta.

Informe $\mathbf{N}^{\mathbf{0}}$ 0124-60 del Departamento de Anatomía Patológica del Hospital San Juan de Dios:

"Descripción macroscópica. La pieza consiste en un útero obtenido mediante histerectomía total, que viene acompañado del anexo izquierdo y de una placenta. La pieza en conjunto pesa 1.125 gramos. Exteriormente la matriz se encuentra deformada y tiene una longitud de $17 \mathrm{cms}$. en sentido vertical, $12 \mathrm{cms}$. en sentido transversal y $7 \mathrm{cms}$. en sentido anteroposterior. El cuerpo se encuentra deformado por la presencia de una placenta que se halla adherido en el intersticio. La serosa uterina es lisa y brillante. Al corte se observa que el miometrio es de color blanco rosado y tiene un espesor de $2.5 \mathrm{cms}$.; hay numerosos vasos sanguíneos de aspecto normal. El endometrio tiene $0.5 \mathrm{~cm}$. de espesor y presenta abundante reacción decidual. El endocérvix tiene una longitud de $5.5 \mathrm{cms}$, permeable y cubierto de moco. El exocérvix no presenta lesiones. Hacia el fondo peritoneal de la matriz se encuentra insertada una placenta de forma redondeada que tiene un diámetro de $18 \mathrm{cms}$. La cara placentaria que normalmente corresponde al útero se continúa sin interrupción con el cuerpo uterino, tratando de hacerlo principalmente a expensas del cuerno izquierdo; es lisa y brillante, con numerosas áreas en las que se observa hemorragia; su cara fetal muestra cotiledones de apariencia normal y en situación paracentral está insertado un cor cón umbilical; unos y otro son macroscópicamente normales.

Al corte la placenta tiene un aspecto normal y deja salir cantidad usual de sangre. Hacia el cuerno izquierdo del útero se encuentra adherido el ova- 
rio correspondiente y el oviducto. El ovario es de forma alargada y mide 7 cms. de longitud, $2 \mathrm{cms}$. en sentido vertical y $1.5 \mathrm{cms}$. en sentido anteroposterior. Exteriormente es de color blanco-grisáceo y tiene adheridas algunas membranas y tejido fibroso. Al corte su superficie es de color blanco-rosado. El oviducto izquierdo tiene una longitud de $17 \mathrm{cms}$; el pabellón es normal; hacia dentro se continúa con la placenta introduciéndose en ella; toda su luz es permeable y tiene un diámetro de $0.3 \mathrm{cms}$.

Descripción microscópica. Los cortes histológicos del cuerpo uterino muestran reacción decidual del endometrio, observándose a veces abundante decidua con necrosis e infiltración inflamatoria, continuándose con el miometrio por medio de células redondas y fusiformes. En los cortes correspondientes a vellosidades coriales los vasos sanguíneos son aparentes y escaso el revestimiento trofoblástico; hay cortes de trompa uterina que presentan môderada esclerosis.

Diagnóstico: Embarazo extrauterino con inserción placentaria en la cara peritoneal del fondo uterino".

\section{COMENTARIO}

La presentación del caso anterior tiene por objeto adicionarlo al número de embarazos ectópicos avanzados que figuran en la literatura colombiana, de cuya revisión completa se encargó el Dr. Jaime Botero-Uribe en 1959.

La historia clínica y el estudio patológico inclinan a pensar en un embarazo abdominal secundario, con posibilidad de haberse alojado inicialmente en la trompa derecha ya que la luz del oviducto izquierdo no mostró alteración alguna en todo su trayecto.

Llama la atención el transcurrir silencioso de los primeros seis meses de embarazo, que encubrió la posible nidación tubaria primitiva y luego su expulsión hacia la cavidad peritoneal.

Suponemos que el dolor se originó al erosionar la placenta algún vaso vecino, irrumpiendo como consecuencia la hemorragia profusa que ocasionó el estado de shock y produjo la muerte fe- 
tal. Esta forma de manifestarse el embarazo abdominal avanzado es por demás curiosa, ya que es lo frecuente que el diagnóstico se haga porque la gestación se ha prolongado, o porque hay ausencia de ruidos y movimientos fetales o por la aparición de dolores que simulan los del parto sin que el cuello uterino se modifique.

La conducta radical que hubo que seguirse confirma lo aconsejado por Browne: cuando en el embarazo ectópico avanzado la placenta, todavía en actividad, se inserta en la superficie peritoneal del útero, obliga muchas veces a removerla junto con éste a causa de las hemorragias que ocasiona. Los casos revisados demuestran que cuando la inserción placentaria se hace en estructuras distintas al útero no tiene complicación el dejarla en su sitio. Esta conducta lógica se verá favorecida cuando la placenta, no importa el sitio en que se inserte, ha dejado de funcionar.

\section{BIBLIOGRAFIA}

1 ACOSTA B. EDUARDO. "Comentarios acerca de dos casos de embarazo ectópico a término". Rev. Col. de Obs. y Gin. 8: 195, 1957.

2 BOTERO-URIBE, JAIME. "Embarazo ectópico avanzado". Rev. Col. de Obs. y Gin. 11: 307, 1960.

3 BROWNE, FRANCIS. "Higiene antenatal y postnatal". 1952.

4 GOMEZ PALACINO, J. A. "Noventa y cinco casos de embarazo ectópico" Rev. Col. de Obs. y Gin. 5: 175, 1954.

5 LONDOÑO MEJIA, A. "Una historia de embarazo abdominal". Rev. Col. de Obst. y Gin. 5: 205, 1954.

6 SANDA, J. M. "Embarazo abdominal, estudio de cuatro casos". Rev. de Obs. y Gin. de Venezuela. 19: 89, 1959. 